\title{
Capsule Commentary on Cully et al., Delivery of Brief Cognitive Behavioral Therapy for Medically III Patients in Primary Care: a Pragmatic Randomized Clinical Trial
}

\author{
Mark D. Schwartz, MD \\ $\mathrm{J}$ Gen Intern Med \\ DOI: $10.1007 / \mathrm{s} 11606-017-4120-0$ \\ (c) Society of General Internal Medicine (outside the USA) 2017
}

Department of Population Health, New York University School of Medicine, New York City, NY, USA.
$\mathrm{T}$ his hybrid effectiveness-implementation trial by Cully et al. tested the impact of brief cognitive behavioral therapy (bCBT), delivered by mental health providers in primary care, on depression, anxiety, and quality of life for veterans with heart failure and/or chronic obstructive pulmonary disease (COPD). ${ }^{1}$ An average of 3.9 weekly bCBT sessions were conducted by 19 mental health providers with 180 patients. Compared to 122 control group patients, the intervention group had improved symptoms of depression and anxiety at 4 months (50\% had a successful treatment response vs. $32.8 \%$ of control group), with effects maintained at 8 and 12 months. The number needed to treat at 4 months for anxiety was 6.3 and for depression was 6.1. Health-related quality of life (QoL) improved for bCBT participants with COPD (not for those with heart failure), but this was not maintained at 12 months.

While this pragmatic trial is referred to as "real world," the sample $(n=302)$ was a curated subset of the eligible population $(n=8835)$ to which one might generalize the findings. Therefore, generalizability to the large number of primary care patients with combined medical and mental illness may be limited. It is likely that participants were more likely to engage in and respond to bCBT than would a less selected population. While no data were provided on a dose-response relationship, it may be that more than four bCBT sessions are needed to achieve a longer-term impact on QoL outcomes for patients with chronic medical conditions and symptoms of depression or anxiety.

Mental health symptoms are common and a key component of quality of life for patients with chronic medical illness and can interfere with treatment adherence and response as well as coping. ${ }^{2} \mathrm{bCBT}$ is effective for patients with anxiety or depression, but strategies for scaling this treatment to more primary care patients with chronic medical illnesses are needed. ${ }^{3}$ Primary care physicians should consider bCBT for such patients if it is available in their practice. Other modalities, such as computer/internet-based CBT, may increase the access and uptake of this therapy, but further study is needed to compare this approach to in-person or telephone-based CBT. ${ }^{4,5}$

Corresponding Author: Mark D. Schwartz, MD; Department of Population HealthNew York University School of Medicine, New York City, NY, USA (e-mail: Mark.Schwartz@nyumc.org).

\section{Compliance with ethical standards:}

Conflict of interest: The author declares that he does not have a conflict of interest.

\section{REFERENCES}

1. Cully JA, Stanley MA, Petersen NJ, Hundt NE, Kauth MR, Naik AD, Sorocco K, Sansgiry S, Zeno D., Kunik ME. Delivery of brief cognitive behavioral therapy for medically ill patients in primary care: a pragmatic randomized clinical trial. J Gen Intern Med. doi: 10.1007/s11606-0174101-3.

2. DeJean D, Giacomini M, Vanstone M, Brundisini F. Patient experiences of depression and anxiety with chronic disease: a systematic review and qualitative meta-synthesis. Ont Health Technol Assess Ser. 2013;13(16):133.

3. Mohr DC, Ho J, Duffecy J, et al. Perceived barriers to psychological treatments and their relationship to depression. J Clin Psychol. 2010;66(4):394-409.

4. Andersson G, Cuijpers P, Carlbring P, Riper H, and Hedman E. Guided Internet-based vs. face-to-face cognitive behavior therapy for psychiatric and somatic disorders: A systematic review and meta-analysis. World Psych 2014;13:288-295.

5. Arnberg FK, Linton SJ, Hultcrantz M, Heintz E, Jonsson U. Internetdelivered psychological treatments for mood and anxiety disorders: a systematic review of their efficacy, safety, and cost-effectiveness. PLoS One. 2014;9(5):e98118. 